\title{
FOLLOW-UP OF PARAPLEGICS AND TETRAPLEGICS AFTER COMPREHENSIVE REHABILITATION
}

\author{
By Roger P. Hallin, M.D. \\ From Kenny Rehabilitation Institute, Minneapolis, Minnesota, U.S.A.
}

IN conducting a follow-up clinic for patients with spinal cord injuries who had been discharged after going through the rehabilitation process, we have become persuaded that psychological adjustment, rather than intellectual capacity or the level or completeness of injury, is the critical factor in determining rehabilitation success. Once a patient has been discharged, his fluid intake, his bowel and bladder needs, and the health of his skin are his responsibility, and he will accept this responsibility only if he accepts his disabled body and values himself and his remaining function enough to avoid preventable complications. Without this acceptance, the most intensive therapy programme and the most ideal vocational plan will be of little overall benefit to him. With it, he not only can avoid regressing but can proceed with education, work, or whatever avenues of living are open to him.

The specific items from our follow-up data reported in this preliminary paper were chosen to estimate psychological adjustment as well as the more obvious effects of level of injury.

Subjects. Patients suffering from spinal cord injury who have gone through the rehabilitation process as in-patients at Kenny Rehabilitation Institute in Minneapolis, Minnesota, are urged to come back at specified intervals for examination, usually as out-patients. The physical evaluation includes a sensory and motor neurological examination. Intravenous pyelography, cystography and cystoscopy are done as indicated. Laboratory studies are few, selective, and of a practical nature, mainly aimed at assessing renal function. The author interviews the patient at some length to gather information about everyday problems encountered since discharge. As the author was also, in most instances, the attending physician during the rehabilitation process, it is thought that a personal physicianpatient relationship is approximated.

Patients are asked to return for their first out-patient evaluation three to six months (depending on distance of residence) after discharge from in-patient comprehensive rehabilitation.

From I January I955 to 22 November I 967,83 patients with traumatic spinal cord damage were discharged from in-patient status.

Between I July I965, and 2I November I967 8I different patients were seen in follow-up examination (33 paraplegics and 48 quadriplegics). Only 42 of these were in the group of 83 discharged since I January 1965. The other 39 were discharged prior to I January 1965, and in two cases as long as I I years ago.

Thus, in spite of our attempt to thoroughly educate patients and their families in the importance of follow-up examination, only half of them have returned. We have made several attempts to contact the other 4I; I4 have responded by letter or telephone, and the usual problem is financial. 
The concept that it is desirable for these people to have regular surveillance degenerates in our experience to the usual episodic medical care. Why don't the others return? Several factors may be responsible, including distance lived from the clinic and associated transportation problems. The most important issue is certainly financial. Our clinic enjoys only limited subsidy and, in our experience, these prople are reluctant to pay for maintenance evaluation. It is possible that some of the patients who do not return have sunk into apathy and lost their will to keep themselves in good condition. Letters and informal contacts suggest, however, that this is most frequently not the case and that patients who have no physical symptoms of trouble are the ones who will not make the effort to come in regularly for follow-up.

This report is based on all those seen in follow-up clinic between I July 1965 and 2I November 1967. Some of these 8I patients have returned to the clinic several times, but only data from the most recent visit have been used in preparing this report. These visits may have occurred at any time within the past two and a half years.

Five of the 8I patients were living in nursing homes at the time of follow-up, the rest lived in private homes.

Results. Table I indicates the type of trauma producing the disability, broken down by age brackets. There is the expected definite pattern of relationship

TABLE I

Type of Trauma by Age

\begin{tabular}{|c|c|c|c|c|c|}
\hline \multirow[b]{2}{*}{ Type of trauma } & \multicolumn{4}{|c|}{ Age at accident } & \multirow[b]{2}{*}{ Totals } \\
\hline & $\mathrm{I}-\mathrm{I} 8$ & 19-30 & $31-50$ & over 50 & \\
\hline Car or other movin & & & & & \\
\hline $\begin{array}{l}\text { vehicle } \\
\text { Water }\end{array}$ & $\begin{array}{r}\text { I0 } \\
6\end{array}$ & $\begin{array}{r}20 \\
6\end{array}$ & $\begin{array}{l}3 \\
2\end{array}$ & 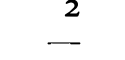 & $\begin{array}{l}35(43 \%) \\
14(17 \%)\end{array}$ \\
\hline Gun & 4 & 2 & - & - & $6(8 \%)$ \\
\hline Fall & 3 & 2 & 6 & 5 & I6 $(20 \%)$ \\
\hline $\begin{array}{l}\text { Struck by falling } \\
\text { object }\end{array}$ & I & $\mathrm{I}$ & 5 & $\mathrm{I}$ & $8(0 \%)$ \\
\hline Hyperextension & - & - & - & 2 & $2(2 \%)$ \\
\hline
\end{tabular}

between age and type of accident. The younger patients, 30 years of age and below, typically become injured in automobile accidents or sports activities. The older patients are injured more often in working situations or in more passive activity.

The qualification 'incomplete', as used in these tables, means the presence of any degree of sensation or voluntary motor function below the level of the lesion. From a practical standpoint, however, the majority of those classified as 'incomplete' function physically like those with complete lesions. 
Tables II and III relate level of injury with certain physical outcomes. Table II simply records the reported occurrence of significant kidney and respiratory infections, since these are largely beyond the control of the individual.

TABLE II

Incidence of Significant Illnesses ${ }^{1}$

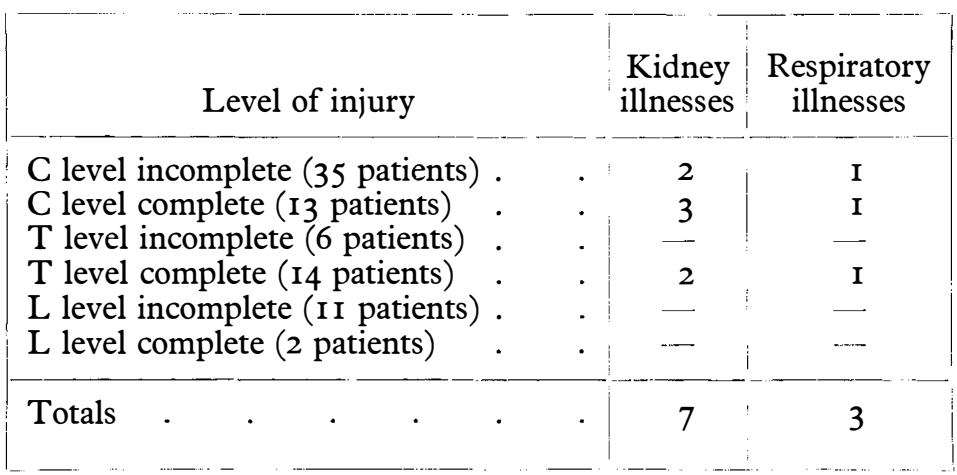

1 Within year preceding interview, about 12 per cent. reported significant illness.

In Table III, three outcomes that reflect upon rehabilitation training are considered. If an outcome indicates lack of application of the training received during rehabilitation, it is recorded. The development of decubiti is considered preventable, so reported skin breakdown is listed. Fluid intake below $2000 \mathrm{cc}$. per day is considered not conducive to good renal function and is recorded. Since almost all these patients lack bowel control but can achieve relative continence by dietary discretion and regular emptying, we arbitrarily listed those patients reporting incontinence more than five times a year. As can be seen from both tables, unfavourable outcomes are more frequent for complete lesions than for incomplete lesions at the same level, and injuries at the L level are less likely to have unfavourable outcomes than lesions at a higher level.

TABLE III

Relationship between Level of Injury and Certain Physical Outcomes

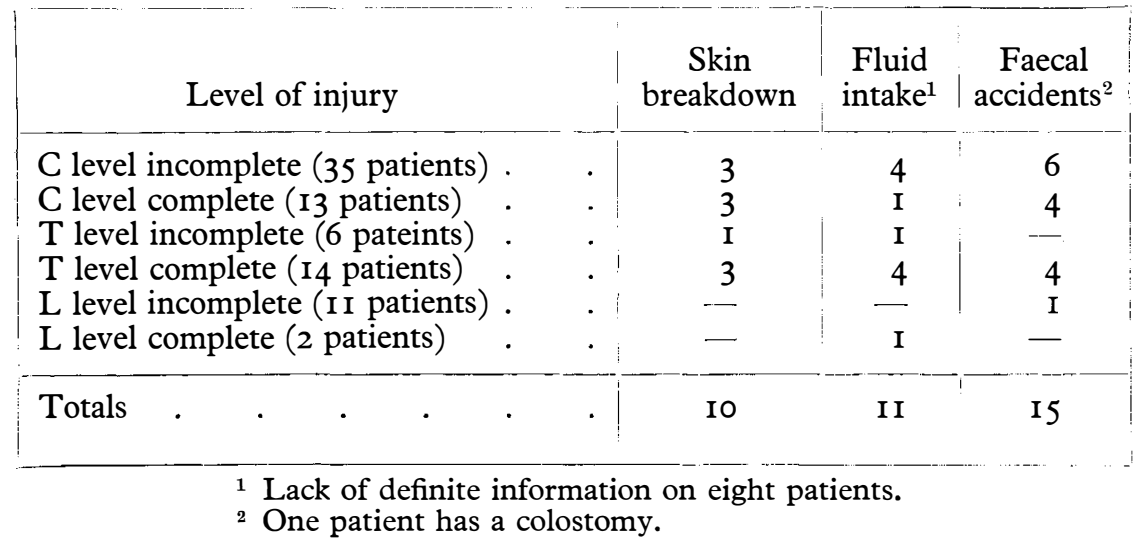


In Table IV, the degree of independence exhibited by the patient is related to age and level of injury. The independent continuum is an estimate of the amount of help the patient needs in getting along in his daily activities. A person who can take care of himself in a wheelchair completely, except that he needs help when faced with a flight of stairs, is classed as more than 90 per cent. independent. One who can feed himself and brush his teeth but needs help for most other activities of daily living is classed as less than ro per cent. independent. This is a gross kind of sorting, based on the judgment of the interviewing physician, and no attempt has been made to separate out the large and important area between Io per cent and 90 per cent.

\section{TABLE IV}

Amount of Independence related to Age and Level of Injury

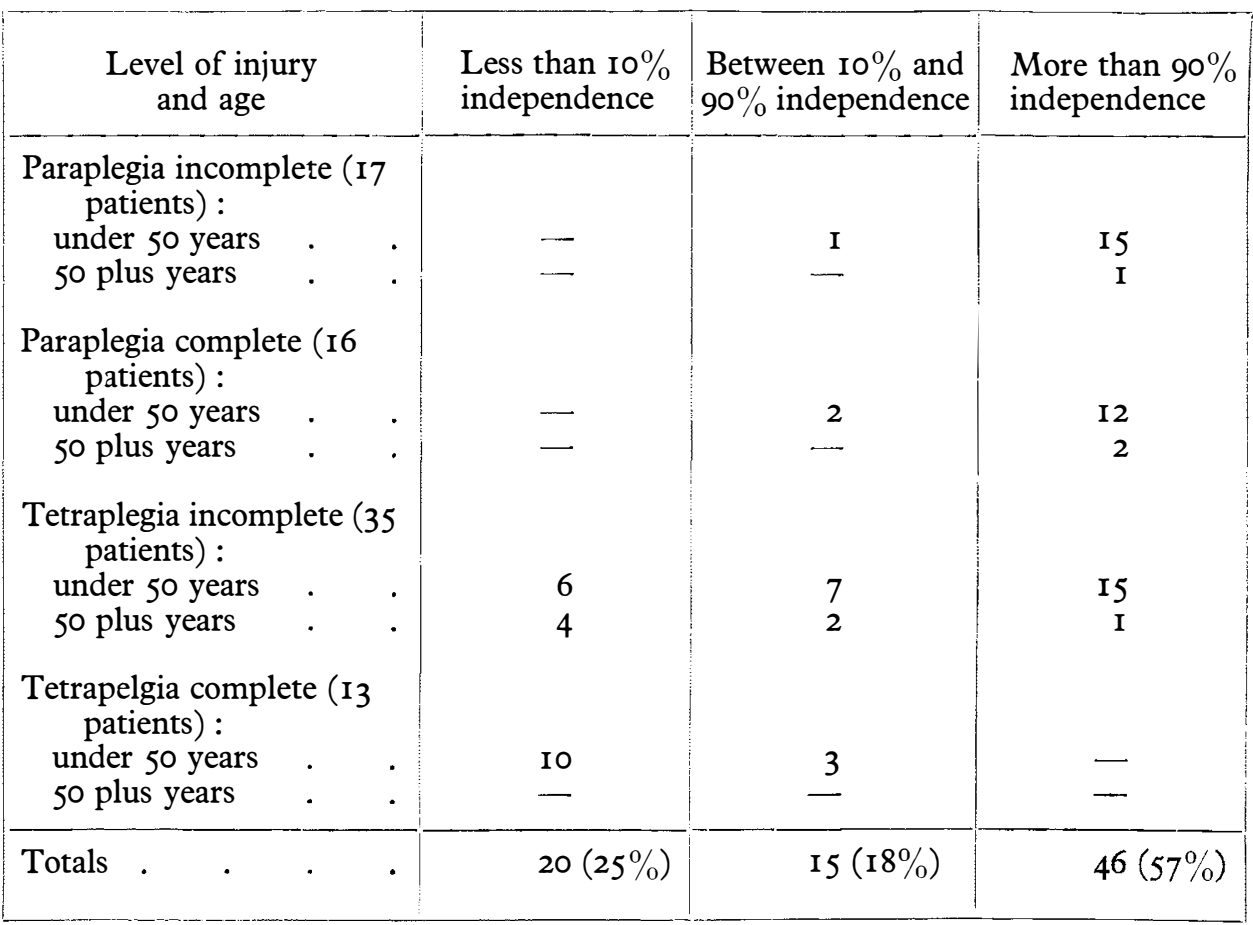

It is evident from the table that level of lesion has a great effect on independence. Almost all of the paraplegics are more than 90 per cent. independent, whereas all 20 patients exhibiting less than Io per cent. independence are tetraplegics. But the data also suggest the depressing effect of age on independence. Thus, four out of seven incomplete quadriplegics 50 years of age and over are less than to per cent. independent, while only six out of 28 incomplete tetraplegics under 50 are in this category.

The above data demonstrate that most of our follow-up patients function with relative independence, do not suffer an unusual amount of illness, and apparently can get along quite satisfactorily at home. However, more information is needed 
for assessing psychosocial adjustment. For one thing, we wanted to know just what our patients did with their time. The author asked each patient questions such as: 'What time do you get up? How much more time does your daily routine take than it would if you did not have disability? How long can you stay up? What do you do when you are up?' and other, similar questions. Of course, information obtained in this manner is not precise and is subject to bias.

TABLE V

Time spent in Self-directed Activities, by Level of Injury and Age

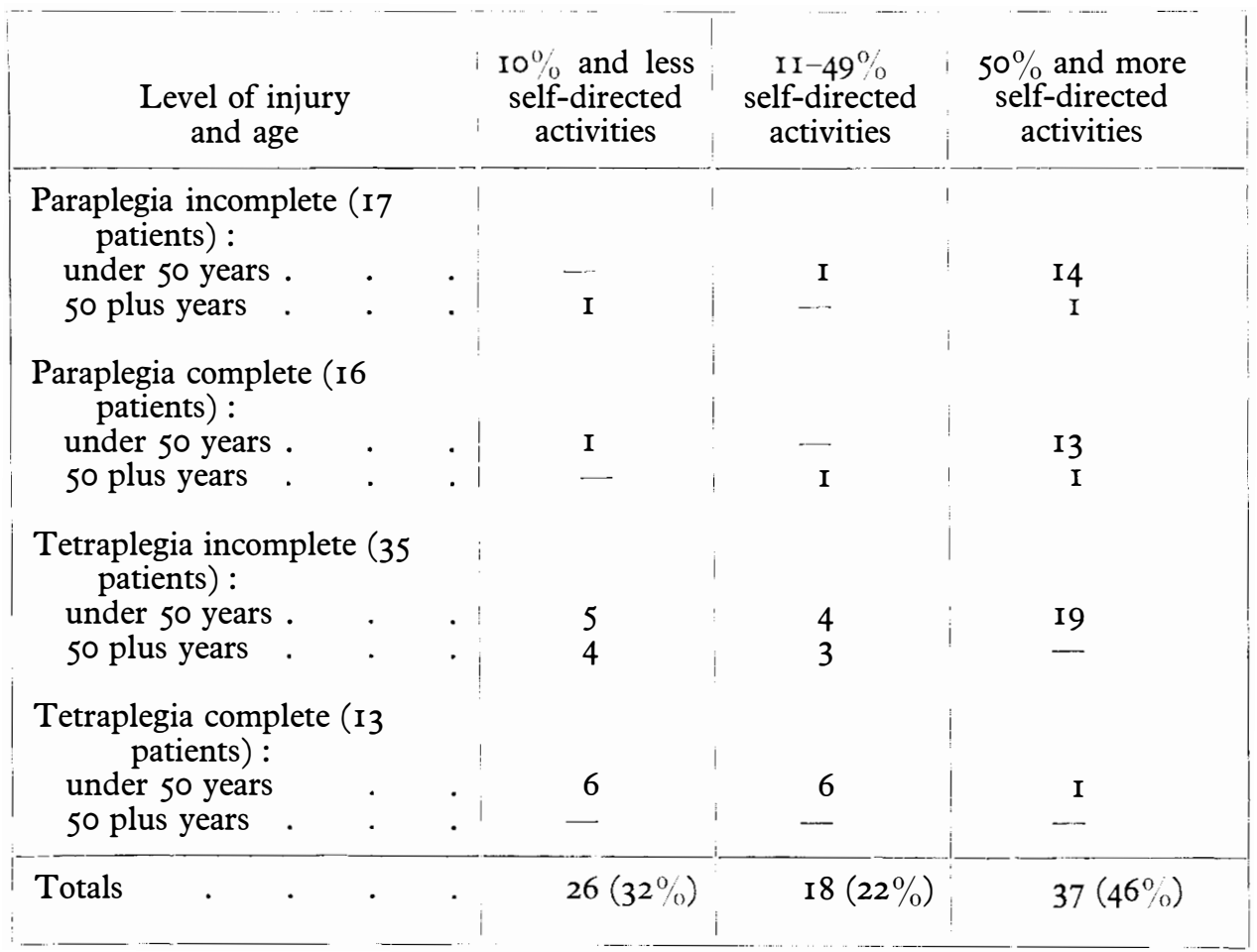

We decided that the answers to our questions would be most meaningful if, instead of merely listing the large variety of activitie's that the patients engaged in, we classed the activities as self-directed or not, and then classified the patients by the proportion of time they spent on self-directed activities (see Table V). Selfdirected activities, as we define them, include schooling, employment, home making, and even doing the decision-making in the home if the actual physical housekeeping is not possible. Being the passive recipient of attention, care, or entertainment is not considered self-directed. The three categories of percentages were again arbitrarily chosen on the basis of clinical judgment.

As Table $\mathrm{V}$ shows, the findings are very similar to those for independence, as one would expect. Level of lesion has a considerable effect, though not as great as in the case of independence. It would appear that some patients who are able to manage their self-care do not go further to directing their own lives. As with 
independence, complete tetraplegics do not often exhibit great amounts of selfdirection in their lives. The depressing effect of age appears again in the incomplete quadriplegia category.

The nature and quality of the marital relationship must surely change in numerous ways, both subtle and obvious, after spinal cord injury. But we have no data on this subject from our material that we feel confidence in. We inquired into change in marital status, and here stability appears. Of our $8 \mathrm{I}$ patients, 40 were married at the time of accident and five of these have been divorced since the accident. Two patients married after their injury and two have fathered one child each.

\section{DISCUSSION}

It appears that the majority of our patients adjust, by and large, very well to their disability. Motivation continues well enough to keep them active, their marriages remain intact, they live in a fairly normal manner, maintain their health and are involved in self-directed activities of some sort. Level and completeness of lesions certainly have their effects, but good psychosocial adjustment can be found in even the most severely injured persons.

Our findings are biased by the number of people who do not return to the clinic for follow-up. Perhaps they are followed by their personal physicians. But, having spent almost 20 years in the general practice of medicine before entering the field of rehabilitation, I know that most physicians have little contact with spinal cord injury and understandably are not familiar with the peculiar problems of these patients. I have no data, but I suspect that, even if these patients are seen by their personal physicians, episodic care is given and comprehensive surveillance is often lacking.

Centralised facilities both for treatment and follow-up of the cord injured seem desirable. However, for these centres to function properly and serve well for maintenance of these people's well being, financial assistance is necessary, not only for the examination but for travel to and from the centre as well.

If such support were possible, we could have a much better picture of the continued life experience of the patient with spinal cord injury who has gone through a rehabilitation programme in a rehabilitation setting. I further believe such minimum care and surveillance is necessary if these people are to continue to live in society in as productive a manner as possible and maintain maximum health. But again, I know of no factual information which clearly shows the difference in outcome between the following three categories:

I. Those who have never been treated by comprehensive rehabilitation.

2. Those who have gone through comprehensive rehabilitation and have returned for maintenance surveillance.

3. Those who have gone through comprehensive rehabilitation and have not had maintenance surveillance.

We in the rehabilitation field have strong feelings about the value of comprehensive rehabilitation and preventive surveillance for the cord injured. But costs are high and we need facts to clear the air. Only then can we make meaningful decisions about the best way to manage this growing segment of our disabled population. 


\section{SUMMARY}

This is a report on 8I patients who have previously been discharged from the Kenny Rehabilitation Institute at Minneapolis, Minnesota, after comprehensive rehabilitation. All these patients had traumatic cord injury. There were 33 paraplegics and 48 tetraplegics. This report deals primarily with the psychosocial adjustment of such disabled individuals living in society. A great majority of these people function with relative independence and seem to have made a quite satisfactory adjustment to their disability. In addition, motivation continues well enough so that they remain in relatively good health. It is recognised that these optimistic findings are biased to some extent by a certain group of such people who do not return for follow-up examination.

\section{RÉSUMÉ}

Ceci est un rapport portant sur 8I paraplégiques ou tétraplégiques qui ont suivi une rééducation au Kenny Rehabilitation Institute at Minneapolis, Minnesota. Il s'agit de lésions traumatiques médullaires : 33 paraplégiques et 48 tétraplégiques. Le but de ce rapport porte surtout sur l'adaptation psycho-sociale du handicapé face à la société. La grande majorité semble s'être bien adapté, avec une indépendance relative, à leur handicap. De plus, la motivation personnelle continue à évoluer suffisamment, de façon à conserver une relative bonne santé. Il est évident que ces propos optimistes sont faussés par un certain nombre de personnes qui omettent de revenir se faire examiner.

\section{ZUSAMMENFASSUNG}

Es wird über 8I Patienten berichtet, die früher im Kenny Rehabilitations Institut, Minneapolis, Minnesota rehabilitiert worden waren. Alle Patienten hatten traumatische Rückenmarksläsionen, 33 Paraplegien und 48 Tetraplegien. Der Bericht behandelt die physchisch-soziale Wiedereingliederung von Versehrten, die innerhalb der Gemeinschaft leben. Eine grosse Mehrzahl dieser Fälle haben eine relative Unabhängigkeit erlangt und haben eine befriedigende Einstellung zu ihrem Körperdefekt. Ihr Antrieb hält an und sie erfreuen sich weiter einer relativ guten Gesundheit. Der Verfasser ist sich bewusst, dass seine Befunde zu einem gewissen Grade zu optimistisch sind, da eine gewisse Zahl der Versehrten nicht zur Nachuntersuchung erschienen ist.

\section{ACKNOWLEDGMENT}

Development and preparation of this material was made possible under Grant RT-2 of the Social and Rehabilitation Service of the Department of Health, Education, and Welfare, awarded to the Department of Physical Medicine and Rehabilitation of the University of Minnesota Medical School, and the American Rehabilitation Foundation.

I want to thank Mrs. Barbara M. Vormbaum and Norman Silberberg, Ph.D., for their assistance in preparing this paper. 